\title{
ATSAR AL-ITTISAQ FI AL-TAMASIK AL- NASH (NAS MIN KITAB AKHBAR ABI AL-QASIM AL-ZAJAJI NAMUDZAJAN)
}

\author{
Abdul Hakim Abd al-Khaliq al-Hasan Sayyid Ahmad
}

ibnalhassan986@hotmail.com

College of Arabic and Social Studies Qossim University Saudi Arabia

\begin{abstract}
The research aims to study the effect of the elements of consistency in the text cohesion through the selected text from the" Akbar abialgasim alzagagy "book, to detect what is possible of the secrets of the artistic languor based on the linguistic objective foundations (rules, this has been through several axe. The study has two axes. The first axis is devoted to the theoretical frame work in which the researcher defined the text, coherence and consistency and it's components, The second come to apply these elements to a text was chosen from "Akbar abilgasim alzagagy" book. The study reached the following findings. The study reached several conclusions, including that because of the various means of consistency the indicative unity of the text is achieved and brought together between its many sentences and inter dependence property owned by these means. The study found that more elements of consistency limitation to text clips assignments, specially indicative assignment indicative element. The ability to high light the most indicative personalized elements are pronouns. Not only this but that the vole of the deletion on the grounds that it is most important means of consistency in the text because of the optimal investment in pronoun assignments which is used as alternative of repeating the subject special the subject of.
\end{abstract}

Keywords: consistency, text, cohesion, Abi Al-Qasim

$$
\begin{aligned}
& \text { ولما كان الحال هذه، كانت الرغبة في أن يكون } \\
& \text { موضوعي متصلا بهذا الفن المعرفي، رغبة في خدمة الدرس } \\
& \text { اللغوي، وبعد جهد استقر الأمر على أن يكون عنوانه:" أثر } \\
& \text { الاتساق في تماسك النص، تطبيقا علن نص مختار من كتاب } \\
& \text { أخبار أبي القاسم الزجاجي. " } \\
& \text { مجال الدراسة بكر، إذ إن البحوث والدراسات التي } \\
& \text { كتبت عن هذا الفن قليلة، مما جعل الباحث يحاول البحث } \\
& \text { عن طريقة يتبعها لتحليل النص تحقيقا للأهداف المرجوة. } \\
& \text { أهمية البحث: 1 1) التحليل النصي لا يقتصر على } \\
& \text { دراسة المستويات ( الصوت ، الصرف، التركيب، الدلالة) } \\
& \text { فحسب، بل يسعى إلى جمع المستويات في إطار كلي يتدرج }
\end{aligned}
$$

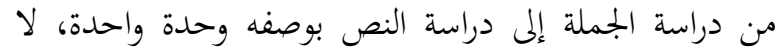

$$
\begin{aligned}
& \text { يعدم فيها أثر المتلقي مقصد المخاطب والسياق .2) علم اللغة }
\end{aligned}
$$

$$
\begin{aligned}
& \text { كانت الجملة في بداية الدرس اللغويّ اللسانيّ وقبل } \\
& \text { أربعة عقود تقريبا، بؤرة الاهتمام من قبل اللغويين ومركز الدوران } \\
& \text { عندهم، واعتبرت الوحدة الأساسيّة للدراسة خصوصا عند } \\
& \text { أصحاب النظرية اللسانية، لكن سرعان ما تغيرت هذه النظرة } \\
& \text { نتيجة الاهتمام الثديد باللغة والتطور الحاصل في جميع العلوم، } \\
& \text { ونقل محورية البحث اللساني إلى درجة أعلى محا كان عليه، } \\
& \text { فتجاوز الأمر الجملة إلى النّص، وبناء على هذا ظهر علم } \\
& \text { جديد يهتم بدراسة النصوص وتفسيرها وتحليلها وهو ما يعرف } \\
& \text { بعلم ( لسانيات النص )وقد احتل هذا الفن المعريف مكانة مميزة } \\
& \text { في الدرس اللغوي الحديث وذلك لحداثته وتنوع موضوعاته، } \\
& \text { التي يأتي في مقدمتها (الاتساق والانسجام ). }
\end{aligned}
$$


بمعرفة شبكة العلاقات النحوية المعجمية وتبياها، فضلا عن علاقات أخرى على المستوى السطحي للنص من حيث العلاقات التي تقيمها أدوات التماسك الرابطة لأجزاء النص، أي: العلاقات التي تؤلف بنية النص. "ووجود أدوات التماسك ل لا يعني أن النص أصبح مفهوما وله معنى؛ وذلك لأن دور هذه الأدوات لا ينتهي بإقامة الربط بين أجزاء النص، بل عليها القيام بتوضيح العلاقات المفهومية وعرضها، أي أنه ليس مجرد خاصية ترتبط بالبنية السطحية للنص في مستوياتما النحوية / المعجمية فحسب، بل هو علاقة دلالية مثلها مثل كل مكونات النظام الدلالي تنتج من خلال عمل نهوي معجمي بشكل واسع، ويمثل إدراكا تلقائيا للخيارات الدلالية ) (hassan,p.6:1976 ، و وإلى ذلك يشير بحيري بقوله:" والتماسك ليس ذا طبيعة نغوية فقط، بل له جوانب دلالية تداولية" (سعيد بيحري، ص. 109، 1997) يتضح من خلال ما سبق الفرق بين مصطلحي التماسك والاتساق الذي سيأتي توضيحه بصورة أدق في المحور الثاني، إلا أنه بالإمكان القول إن التماسك تعبير سطحي لعلاقات التناسق فهو أداة لتوضيح العلاقات المفهومية وجعلها واضحة بينة، كما أنه خاصة جوهرية من خواص النص، بخلاف الاتساق الذي هو مظهر من مظاهر تقويم القارئ للنص، والتماسك أمر موضوعي وجوده النص، في حين أن الاتساق ذاتي يعود للمتلقي.

\section{مفهوم النص لغة}

قبل الإشارة إلى ماهية النص، لا بد من الإشارة إلى له

ما أوردته كتب المعاجم لفذا المصطلح؛ فالصورة المعجمية لأي لفظ في العربية تمثل المرجعية الأولى له باعتبار دلاليته الأولى، فالحالة المعجمية للألفاظ تتثل الصورة الأساسية لمحيطها الدلالي.

يقول الخليل بن أحمد:" نصصت الحديث إلى فلان

نصا، أي: دفعته،...6، والمنصة التي تقعد عليها العروس...6 والماشطة تنص العروس، أي: تقعدها على المنصة، وهي تنص،
النص علم متداخل، حيث يعمد إلى منهجيات العلوم الإنسانية الأخرى والاستعانة بها في تحليل النصوص (ل) الاجتماع، النفس...) ومن ثم يوصف بأنه علم متداخل فهو ججموعة علوم متشابكة. 3) ـ فتحه المجال لدراسات جديدة، تدفع الطلاب لارتياد البحث اللغويّ المرتبط بالتراث اللغوي القديم.

أهداف البحث: تمدف الدراسة وبشكل مباشر إلى دراسة أثر عناصر الاتساق في تماسك النص من خلال نص

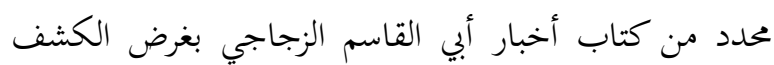
عما يتيحه هذا النص من أسرار استنادا إلى أسس لغوية موضوعية، ويتم ذلك من خلال مباحث يتم عرضها في هيكل البحث.

ومنهج البحث، اتبع الباحث في بكثه المنهج الوصفي المعتمد على التحليل، وهو منهج يعتمد على وسائل التعليل والتحليل والتفسير، من خلال كتب النحو واللغة والمعاني. مفيدا من معطيات الدرس اللغوي الحديث وبخاصة نخو النص.

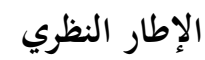
مفهوم التماسك النصي

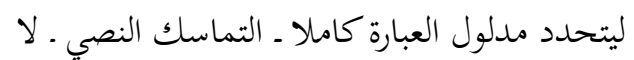
بد من الإشارة إلى مدلول طرين العبارة ( التماسك ) ، ومن ثم ( النص ) ومن خلالفما يتبين لنا مقصود قولمم:

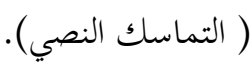
أطلق العلماء على مصطلح التماسك مصطلحات عدة، أبرزها: الانسجام (الأزهر الزناد، ص15، معلى 1993) ، والربط النحوي، والسبك أو الالتحام (تمام حسان،ص.59، 1993) ، وقد جمع العلماء بينه وبين مصطلح الاتساق فلا يرون فرقا دلاليا بينهما، وإن كان ذلك (Coherence) يحتاج إلى ضبط وإحكام وتدقيق. والتماسك على حسب ما جاء في كتاب هاليداي ورقية حسن، هو: مجموعة من المواد اللغوية الموجودة في كل لغة، والمستخدمة لربط أجزاء نص ما بعضها بعضا. فالتماسك لك يدور في الدراسات النصية حول بنيتها السطحية التي ثتم 
وأصحاب المذهب اللغوي المعروف بـ ( تحليل الخطاب ) لا يرون فرقا بين النص والخطاب، أو لربما تجد

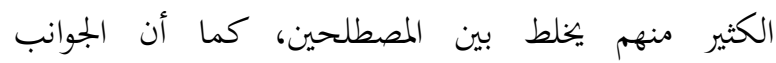
المستخدمة في تحليل الخطاب هي نفسها المستخدمة في تحليل النص، بل بعضهم يصرّح بعدم الفرق بين المصطلحين:" فالنص

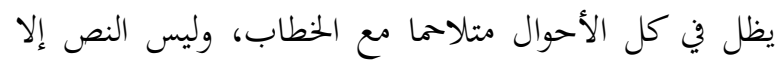

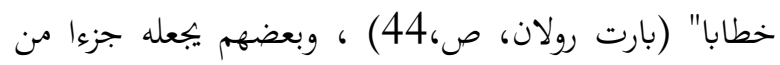
الخطاب، وأن مجموعة النص هي التي تكون خطابا. أما هاليداي ورقية حسن، فيقولان:" تستعمل كلمة ( نص) في علوم اللغة للإشارة إلى أي مقطع منطوق أو لماتيه

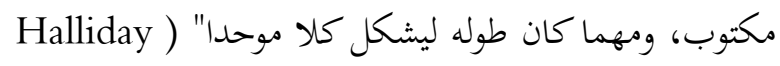
. (and Hassan,p.1 وقد اعترض جون لاينز على التعريف التقليدي للنص بأنه

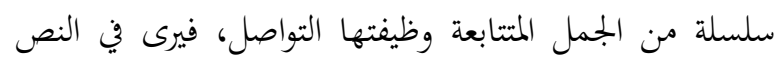
أنه:" ليس مجرد وحدات متصلة مع بعضها في سلسلة، إنما ينبغي ربطها بطريقة مناسبة من حيث السياق، وعلى النص في تهردي

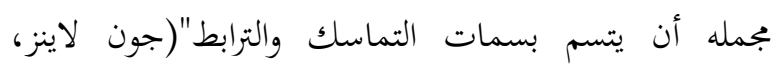

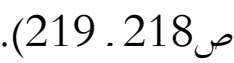

أما كريستال وهانيه فلم يقصرا تعريفهما للنص على

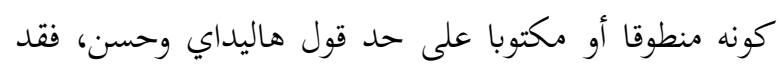
أدخلا جوانب أخرى تشمل علامات الطريق والمحادثات والتقارير الإخبارية والصور الرمزية والقصائد والإعلانات

.(David Crystal,p.23:2011)

وهذه الجوانب نجدها تدخل تحت مفهوم النص اعتمادا على وظيفته الأساسية ( التواصل) والتي تعرف بسمات

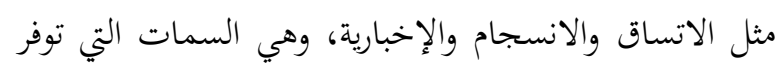

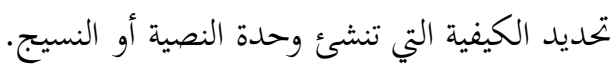
وليست التواصلية هي الوظيفة الوحيدة للنص،

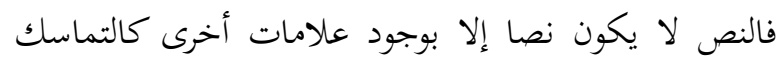

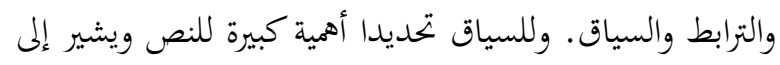

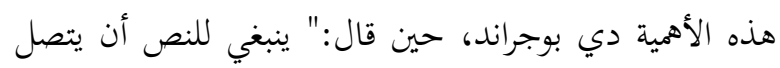
بموقف يكون فيه ( حدوث موقف) تفاعل فيه مجموعة من
أي: تقعد عليها، أو تشرف لترى من بين النساء" (الخليل بن

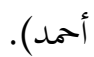

أما ابن منظور ففي تحديده لدلالة مادة ( ن ص ص):" نصّ القرآن، ونص السنة، أي: ما يدل ظاهر لفظهما

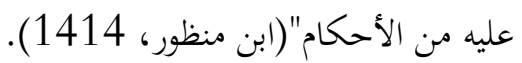
ويسند الأزهري إلى كعب قولا، وهو يجدد دلائ دلالة المصطلح، فيقول:" روي عن كعب أنه قال:" يقول الجبار: احذروين فإني لا أناص عبدا إلا عذبته، أي: لا استقصي عليه

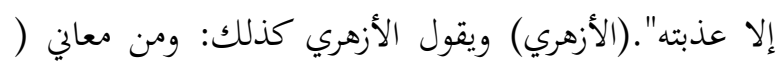

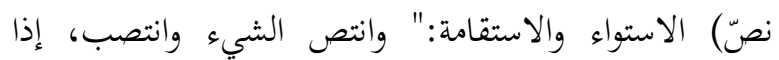

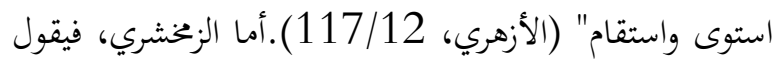

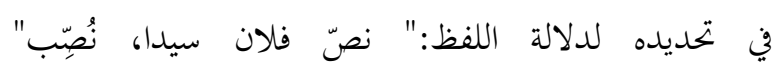

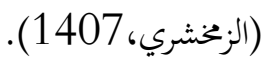

من خلال ما أورده أصحاب المعاجم يتبين لنا أن أصحاب هذه المعاجم وإن اختلفت الألفاظ التي استخدموها

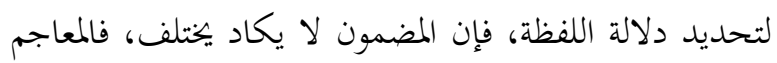
في مجملها تشير إلى أن المقصود بالنص ( الكشف والف والظهور)

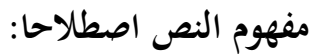

لن بحد تعريفا دقيقا للنص تحت مصطلح نص، النح فحال النص كحال الجملة التي ما عرفها القدماء من علماء اللغة تحت مصطلح جملة، وإنما عرفت تحت مفهوم مصطلح آخر، ليس هذا فحسب بل ثمة اختلافات شديدة لربما وصلت

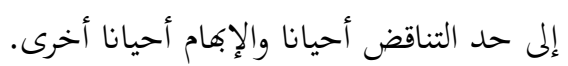

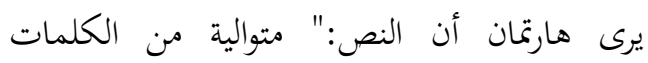

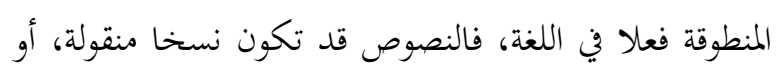

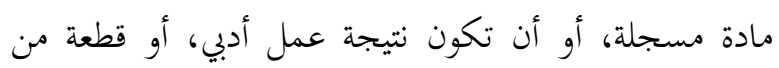
معلومات، نصّ رسالة مثلا".(Hartman,p.238) فهارتمان

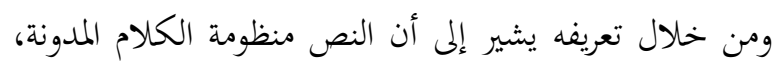

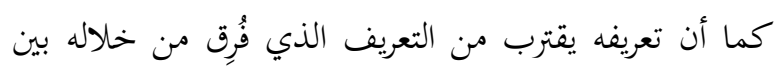

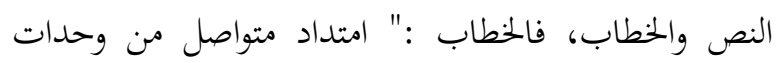
لغوية أكبر من الجملة المنطوقة منها خاصة" (Hartman) ،أما النص فهو تدوين من الامتدادات اللغوية. 
أما عن هذه القواعد والوسائل التي أجمع العلماء

$$
\text { عليها، فبياها كما يلي: }
$$

1/ الإحالة: وهي من أهم وسائل الاتساق وأكثرها شيوعا ئاس داخل النص، أو في الكلام، والإحالة خاصية تمتلكها اللغات وهن جميعها، وهي:" مفهوم دلالي يجيل على التعالق بين عنصرين،

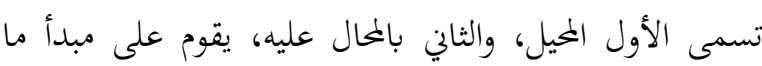

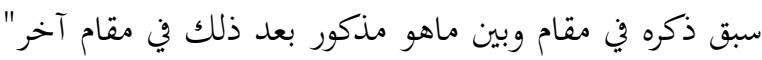
(مفتاح خربوش، ص، 28، 2008). وبهذا فهي:" لا تخضع لقيود نهوية، إلا أفا تخضع لقيد دلالي، وهو وجوب تطابق الخصائص الدلالية بين العنصر

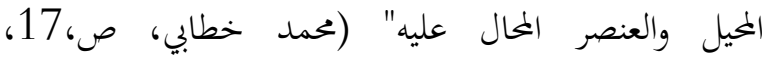

$$
\text { وتقسم الإحالة إلى قسمين: }
$$

1. الإحالة الداخلية (Endophora) وهي بدورها تنقسم

أ/ الإحالة على سابق (Anaphora) وتعني أن المفردة تحيل

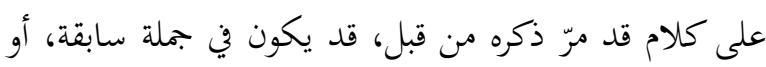

$$
\text { جملة أسبق منها. }
$$

ب/ الإحالة على لاحق (Cataphora) ويقصد بها أن المحيل يشير هنا إلى شيء لاحق له، أي أنه يستمد تأويله من

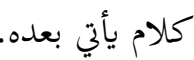

2 ـ الإحالة الخارجية (Exophora) ويطلق عليها ( الإحالة المقامية) ويعني أن المقام الذي يقال فيه النص يسهم في اتساقه، من خلال فهم ما يحيط النص من أمور تساعد في فهمه،

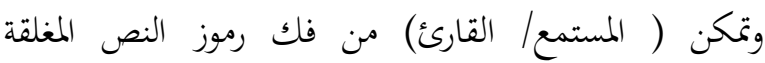
بالاستعانة بما يعطيه المقام من عون. ويصنف هاليداي وحسن الإحالة إلى ثلاثة أنواع :(Halliday and Hassan,p.43) 1/ الإحالة الشخصية: ويتم هذا النوع من الإحالة بالضمائر. 2/ الإحالة الإشارية: ويتم هذا النوع من الإحالة بالإشارة،

$$
\text { حسب القرب أو الزمان أو الحياد. }
$$

المرتكزات والتوقفات والمعارف، وهذه البيئة الشاسعة تسمى سياق الموقف" (روبرت دي بوجراند،ص، 91، 1998). فالنص كل مترابط الأجزاء بحيث يؤدي الفصل بينها إلى عدم وضوحه، كما يؤدي عزل عنصر من عناصره وإسقاطه إلى عدم الفهم، وهذا التصور يتعلق بمفاهيم الربط النحوي ووسائله والتماسك الدلالي ووسائله والسياق التركبي وعلاقتهنه

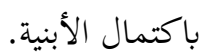
ثانيا: مفهوم الاتساق وعناصره أشرت في بداية البحث إلى أن الصورة المعجمية لأي لفظ تمثل المرجعية الأولى له باعتبار دلالته الأولى، فالحالة المعجمية لأي لفظ تمثل الصورة الأساسية لمحيطها الدلالي. أما عن مفهوم الاتساق في أمهات كتب المعاجم،

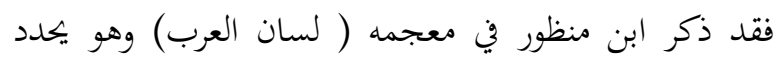

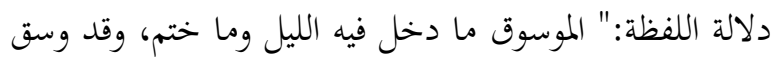

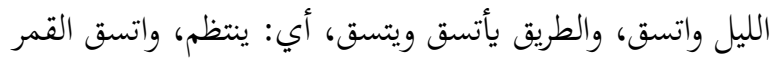

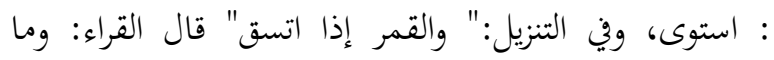
وسق، أي: وما جمع وما ختم، واتساق القمر امتلاؤه

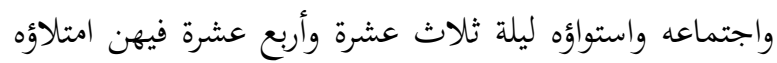
واتساقه" (ابن منظور). وهذا ما أشارت إليه بقية المعاجم؛ فالمعاجم في

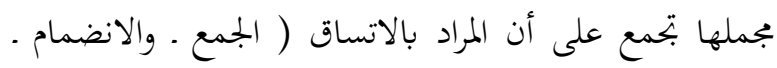
والامتلاء). فاتساق النص بناء على ذلك يعني جمع أجزائه، وضم بعضها إلى بعض، واستواء النص من حيث الدلالة،

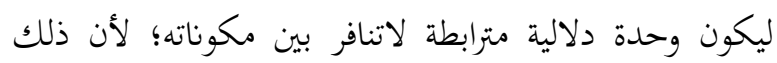
التنافر يخرج النص من دائرة النصية، ولا يعد بذلك نصا.

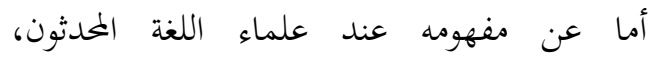

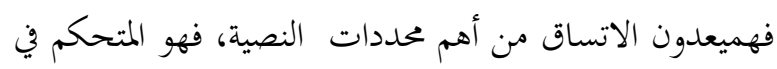
البنية السطحية الشكلية للنص، وبه تتحقق خاصية الاستمرارية

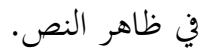
فالاتساق:" مجموعة القواعد الثكلية التي تربط العناصر اللغوية، بتدرج تصاعدي من أصغر وحدة لغوية إلى إلى

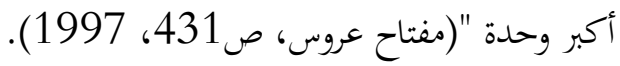


تعالى (ثم يخرجكم طفلا) ـ فقلت: ليس هذا من ذاك لأن

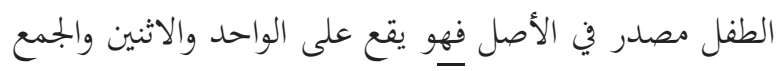
بلفظ واحد فتقول: " هذا طفل، وهذان طفل، وهؤلاء طفل

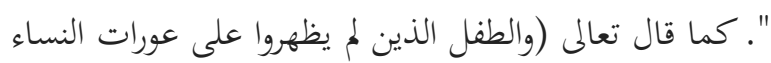
" المفل في الآية موضع أطفال فكأنه قال ثم ميخرجكم أطفالا.

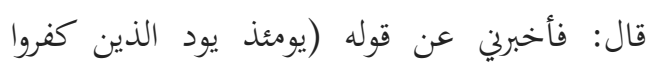

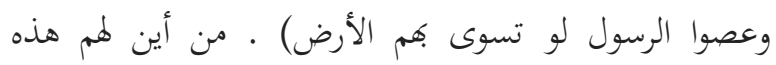

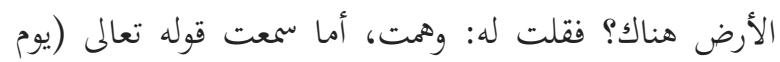

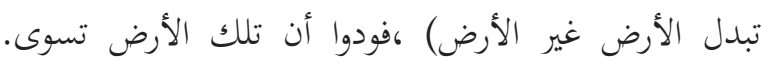

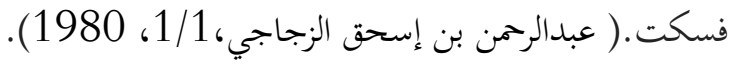
أولا: الإحالة

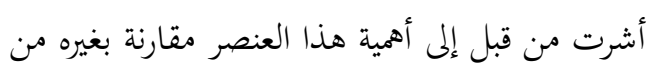

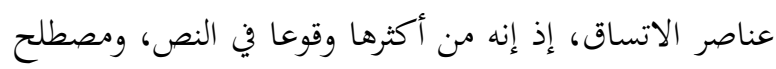

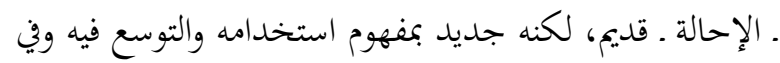

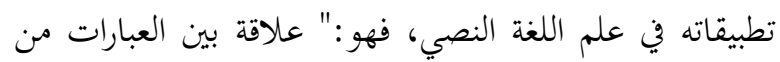
جهة وبين الأشياء والمواقف في العالم الخارجي الذي تشير إليه

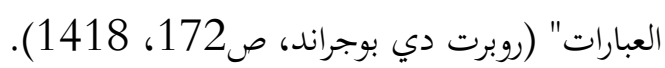

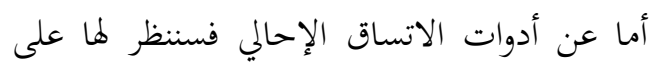
حسب تقسيم يقسمها إلى قسمين، هما: الضمائر، وأسماء

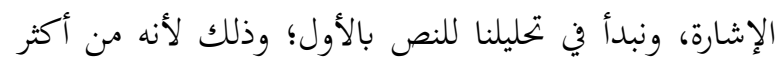

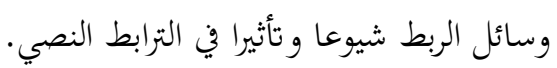

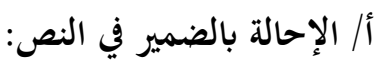

يرى بعض العلماء أن الربط في النص لا يكون إلا

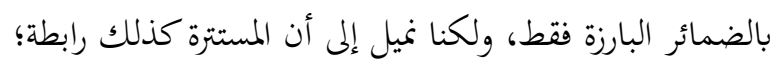
وذلك لأها تدرك بالعقل وتستنبط من خلال المعنى. والضمائر في النص كثيرة، ففي أول النص نجد إحالة المعنا

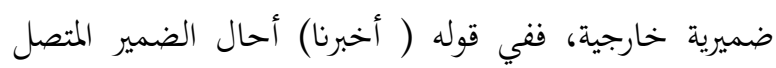

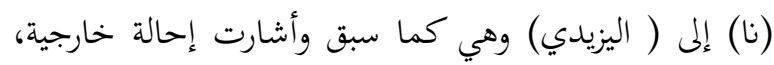

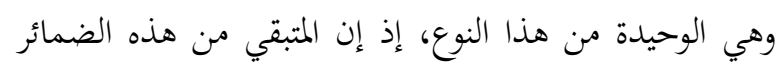

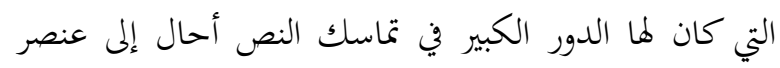
داخله، فالضمائر المتصلة في قوله: " عمه، يرفعه ، يجيئني،

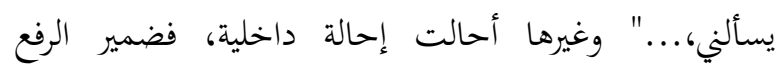

3/ الإحالة المقارنة: وهذا النوع على صنفين: الأول: عام

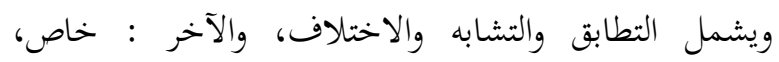
والقسم الخاص بدوره إلى نوعين: كمي ونوعي. 2/ الإبدال: ويقصد به إبدال عنصر لغوي بعنصر لغوي آخرو، وقد قسمه العلماء إلى ثلاثة أقسام:

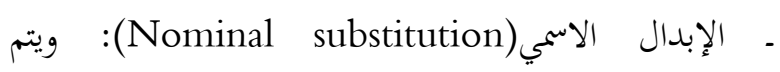
باستبدال اسم في النص باسم آخر. ـ الإبدال الفعلي(substitutionVerbal): فعل في النص بفعل آخر.

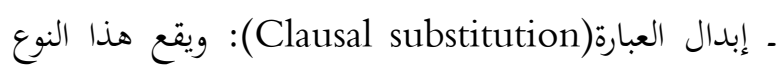
حينما تستبدل عبارة في النص بكلمة واحدة تشير إلى العبارة المستبدلة (Halliday and Hassan,p.138).

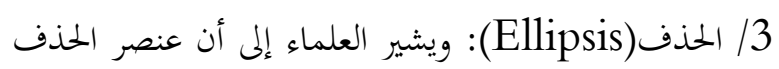

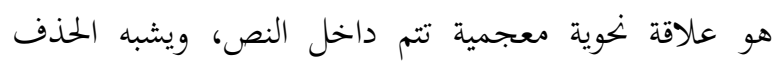

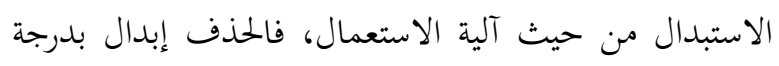

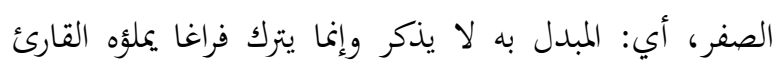
باعتماده على النص السابق، والحذف بدوره قسم إلى ثلاثة

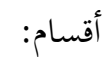
ـ حذف اسمي: ويقع الحذف هنا داخل المجموعة الاسمية.

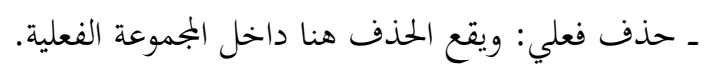
ـ حذف العبارة: والحذف هنا يشمل العبارة اسمية أو فعلية.

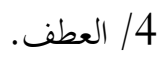

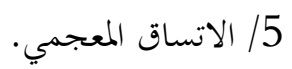

\section{عناصر الاتساق في النص وأثرها في تماسكه}

النص: عناصر الان

أخبرنا اليزيدي عن عمه أبي الشيخ يرفعه إلى أبي

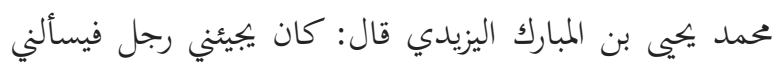

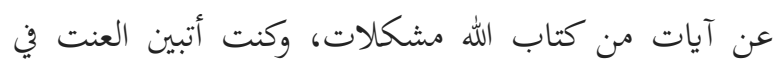

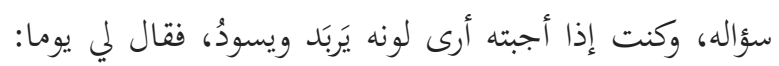

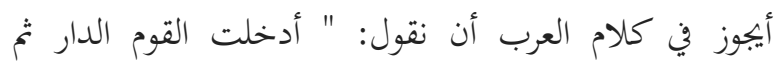

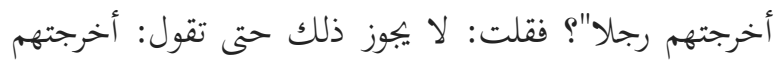
رجلا رجلا، تقوله في تفصيل الجنس. قال: فكيف قال الله 


$$
\text { أ/ ضمائر الرفع: منها: }
$$

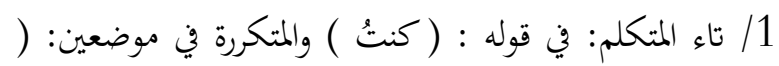

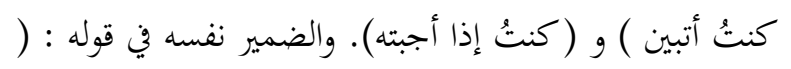

$$
\text { أدخلتُ ) و ( أخرجتُ). }
$$

2/ واو الجماعة: وجاءت في موضع واحد، قوله : ( يظهروا ).

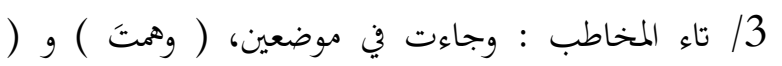

سمعتَ ).

فكما سبق وأشرت، فالضمائر في مجملها تدور حول

بطلي النص ( اليزيدي ) و ( الرجل السائل) ماعدا ضمير

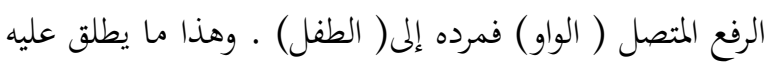

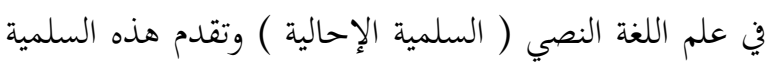

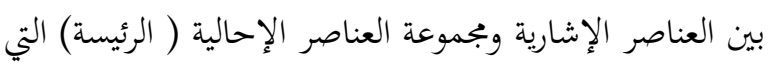

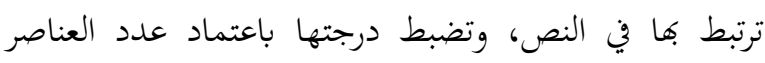
الإحالية التي تعود على كل عنصر من العناصر الإشارية، فأهم عنصر في النص يرتبط به أكبر عدد من العناصر الإحالية التي لتعني

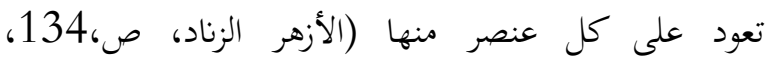

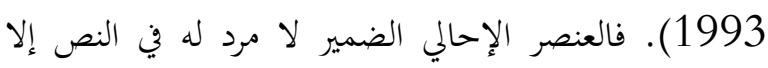

$$
\text { ب/ ضخصية الراوي، وشخصية السائل. }
$$

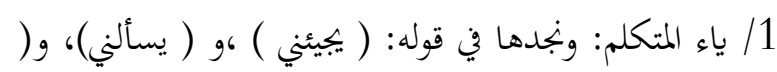
أخبرني) ومردها في إلى كل اليزيدي.

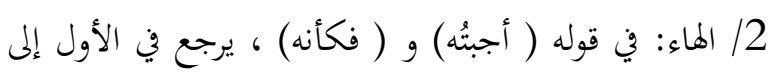
السائل، وفي الآخر إلى الله عز وجل.

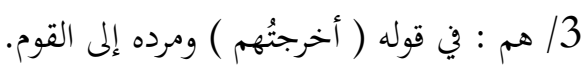
/4 كم : في قوله ( يخرجكم ) ومرد الضمير إلى الخلائق.

$$
\text { ج/ ضمائر الجر: }
$$

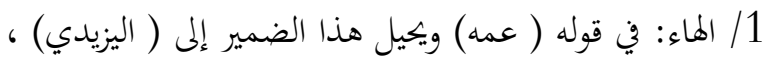

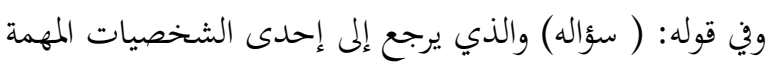
في النص ،وهي شخصية ( السائل ) . 12 هم: وورد في موضعين ( بكم ) و و ( لهم ) ومرجعه : الكفار.

ولا ننسى دور الضمير المنفصل في الترابط النصي، إذ

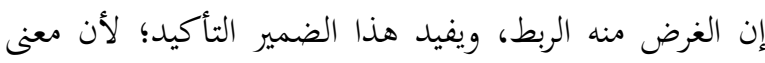

المتصل في الكلمة الأولى أشار إلى اليزيدي، والهاء في ( يرفعه )

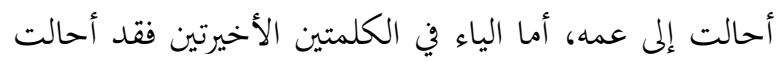

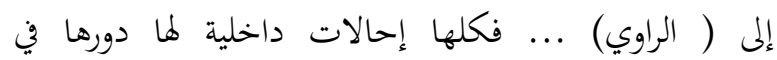

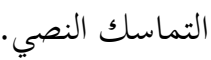
والضمير لا بد له من مرجع يعود إليه ويكون ملفوظا

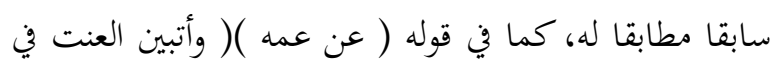

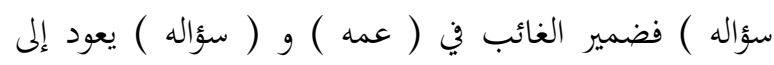

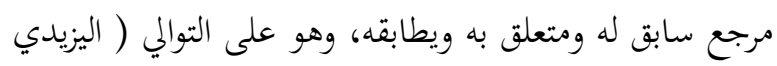

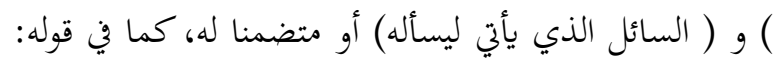

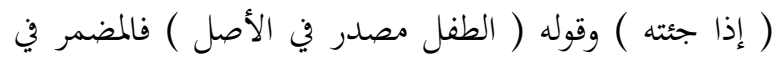
الأولى عائد على السؤال المتضمن له ( سؤاله) أما في الثاني فعائد على ( المصدر)، أي: فالمصدر يقع على الواحد والاثنين.

وقد يدل على المحيل ( الضمير ) السياق ثقة بفهم السامع، وهذا واضح من خلال قول الراوي:( أرى لونه ) أي:

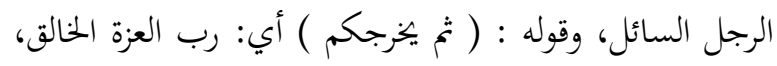

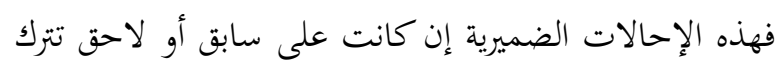
للسامع أو القارئ ليفهمها ويعرفها من خلال السياق.

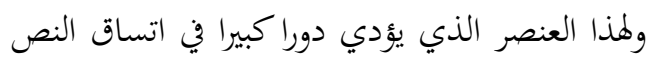
وتماسكه، متقدم يرجع إليه - بعضها تقدم لفظي، والآخر معنوي - أو متأخر عنه.

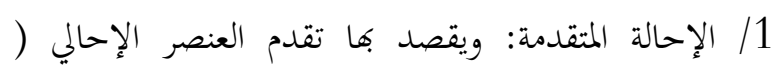

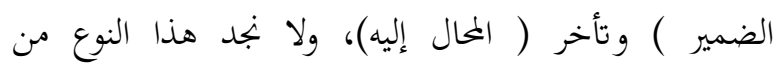

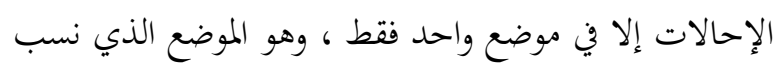

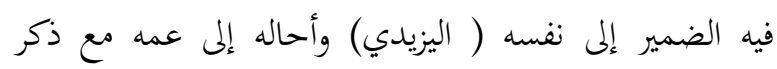

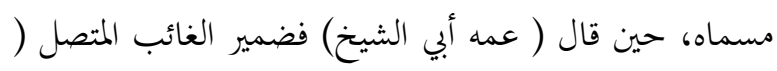

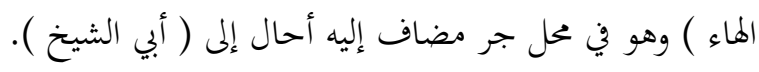

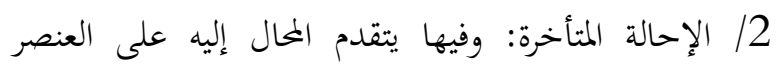

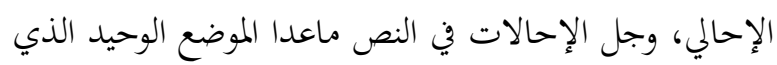

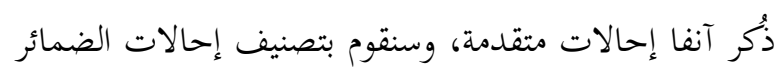

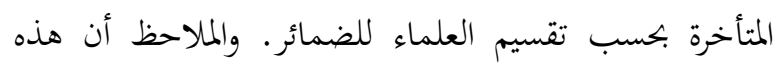

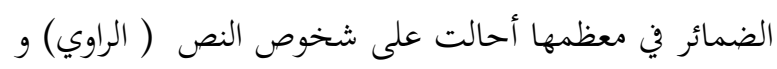
( السائل ). (ائل ). 
تحيل إلى سابق أقرب، هو قوله تعالى:" ثم يخرجكم طفلا"، والعنصر الإحالي الآخر اسم الإشارة ( ذا ) المرتبط بأداة المقارنة

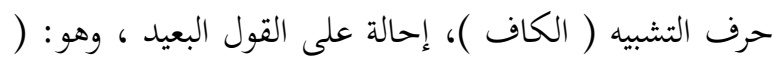

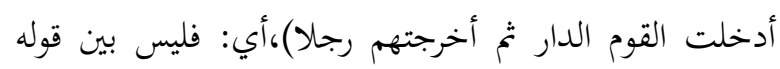

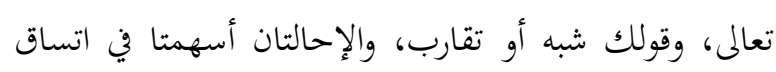
النص وتماسكه، وذلك حينما تقوم بربط اسمي الإشارة بالمشار إليه .

والإحالات الرابعة والخامسة والسادسة بأسماء الإشارة

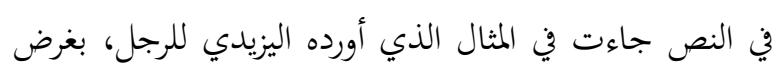

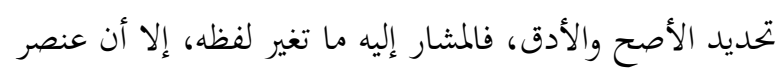

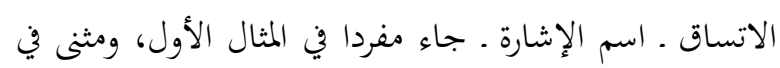

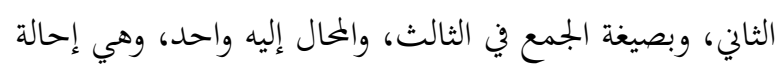

$$
\text { على متقدم غير محسوس. }
$$

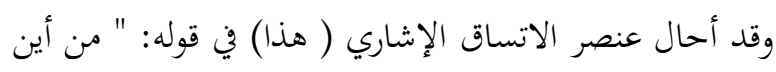

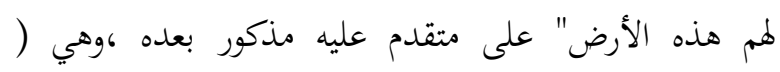
(الأرض). أما اسم الإشارة الثامن ( هناك)، وهو لمحال بعيد

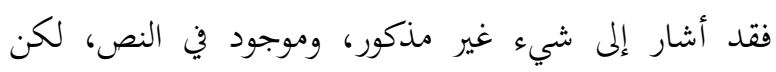

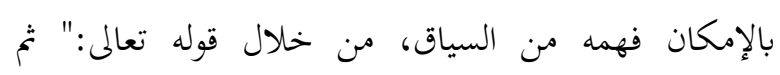

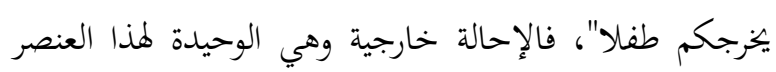
الإحالي.

وأشار اسم الإشارة (تلك) في غاية النص إلى لاحق

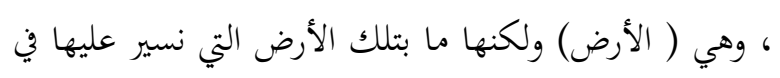

$$
\text { الدنيا، فهي أرض غير هذه. }
$$

فهذه العناصر الإحالية التسعة كان لها ذلك الك الدور

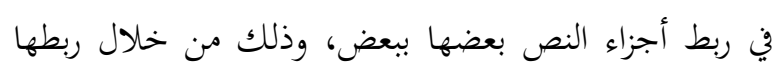

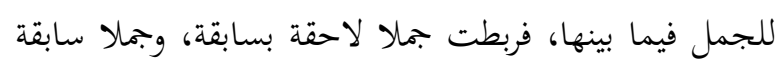

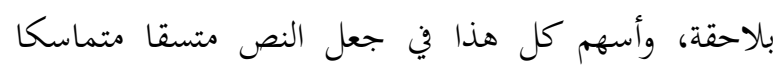
مترابطا.

ثانيا: الحذف:
قولك: زيد هو قائم: زيد نفسه القائم، لكنه تأكيد في المستوى

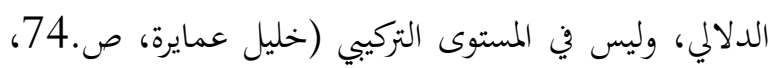

وجاء الضمير المنفصل في النص مرة واحدة، في قوله

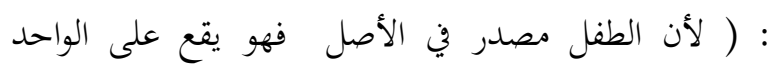

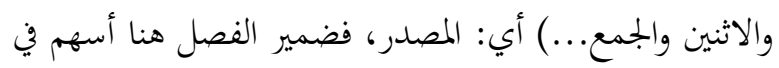
تحقيق الصلة المعنوية بين طرفي الإسناد، حيث كان العندان عنصرا محيلا

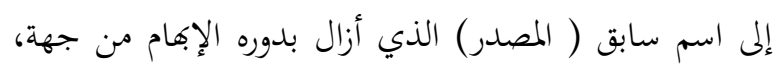

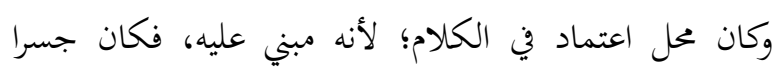
تركيبيا دلاليا له دوره في الكلام.

فالإحالة بالضمير من أكثر الوسائل قوة في صنع التماسك الدلالي للنص وبتسيد وحدته العامة، وتتجلى أهمية

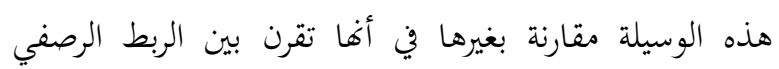
والمفهومي، أي بين اللفظ والمعنى.

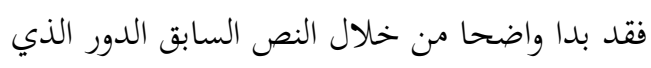
أدته الضمائر في إحكام النص وتماسكه، فقد كانت الإحالة بها إلى عناصر متقدمة أو متأخرة عاملا قويا أسهم إلى جوار غيره من العناصر الأخرى في ربط أجزاء النص.

\section{ب/ الإحالة باسم الإشارة:} لاسم الإشارة دور في تماسك النص شأنه في ذلك الإنكارف شأن عناصر الاتساق الأخرى ( الإبدال ـ الحذف ل... وغيرهما) فيما للإشارة أن تكون على سابق في النص أو لاحق. الإن. وقد جاء اسم الإشارة في النص في تسعة مواضع، وفي هذه لنه المواضع كلها كان له ذاك الدور في إحداث التماسك النصيّ. وأول المواضع التي ورد فيها، قوله: ( لا يجوز ذلك ) حيث لم تتقدم على اسم الإشارة ( ذا) أداة التنبيه ( الهاء )

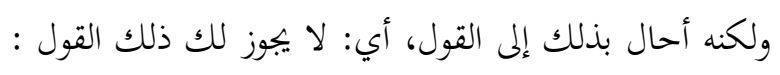

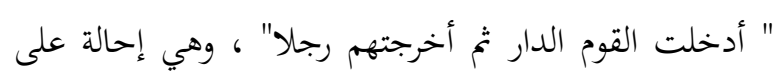

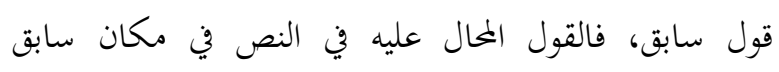

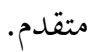

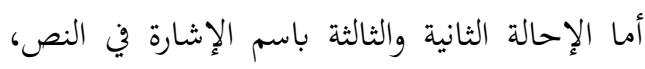
ففي قوله :( ليس هذا من ذاك ) إحالتان على سابق، الأولى بلى الإنطارة 
والمحذوف في قوله: (ليس هذا من ذلك) جملة

القول، أي: ليس قوله تعالى:" ثم يخرجكم طفلا"، كقولك في هن

$$
\text { ذلك : " أدخلت القوم الدار ثم أخرجتهم رجلا". }
$$

فالحذف آلية المنتج في النص به يختصري

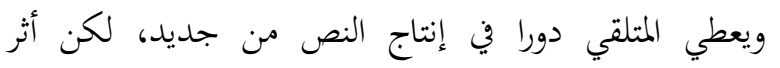

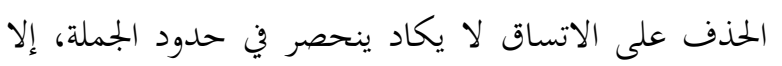

ما كان من تقدير المتلقي للمحذوف اعتمادا على السياق.

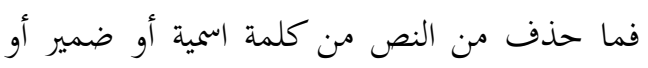

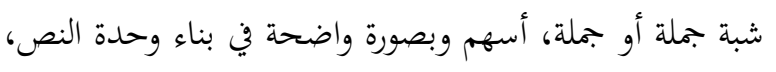

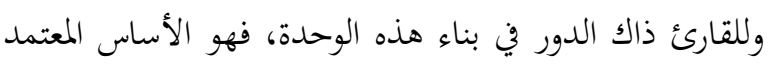
عليه في ملء الفراغات التي تركها المحذوف من النص، فتراه

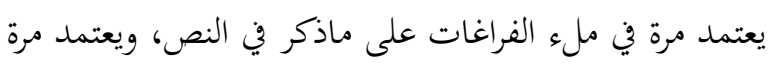

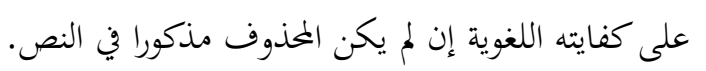

\section{ثالثا: العطف:}

هو أحد الأدوات التي تؤدي إلى التماسك النصي،

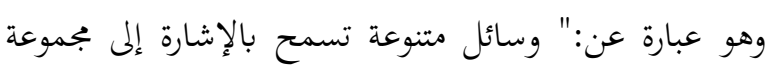
من المتواليات السطحية بعضها ببعض، بطريقة تسمح بالإشارة

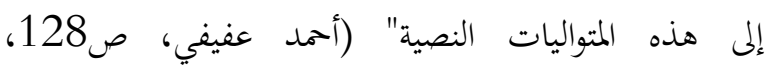
.(2001

وتمثل أدوات العطف روابط شكلية لها معان دلالية

وفقا للعلاقات الموجودة بين الجمل على مستوى النص، وهذا

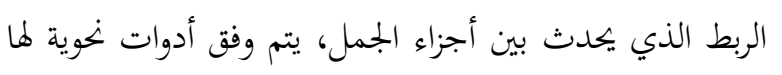

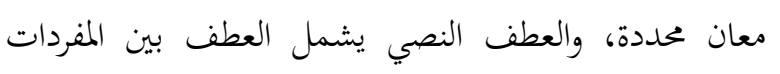
والجمل والفقرات والنصوص، والعطف يعين على استمرارية

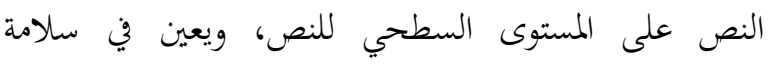
التماسك الخطي، ويسهم في إنتاج الدلالية الكلية للنص. أما عن العطف باعتباره وسيلة من وسائل الاتساق وئناج

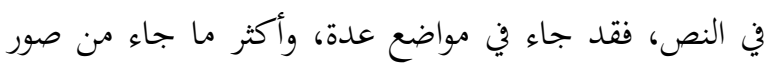
العطف فيه، عطف جملة فعلية على أخرى، كقوله :" يجيئني

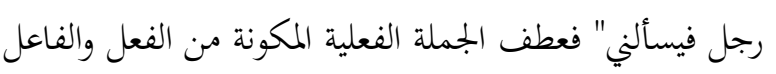

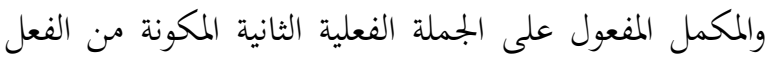

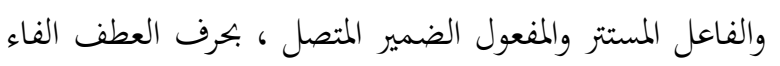

وهو " باب دقيق المسلك لطيف المأخذ، وإن الحذف أبلغ من الذكر وإن المتكلم يكون أكثر بيانا إذا لم يبن

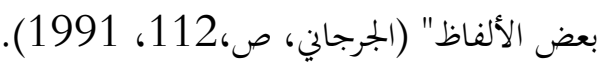

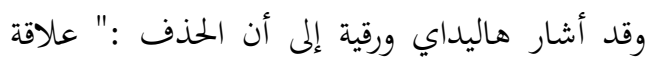
داخل النص، وفي معظم الأمثلة يوجد العنصر المفترض في إن

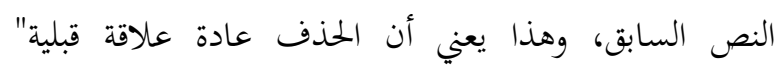

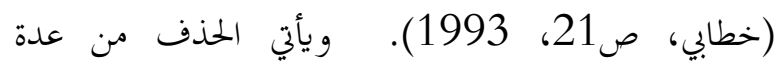
أساليب، أهمها: الإشغال، والاختيار، والتعميم، والبناء (ابن يحيى الطاهر ناعوس، ص334 ، 1433). والنص الذي بين أيدينا لا يخلو من محذوف، وجملة

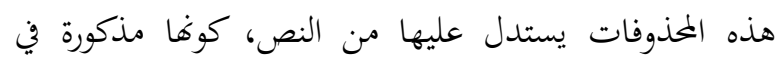
النص، أو تعرف من خلال السياق، إذ يمكن للقارئ أن يملأ الفراغات التي يتركها الحذف، وهو مذكور في النص، إلا أنا لانجد من المحذوف في النص إلا القليل، ومن أنواعه التي

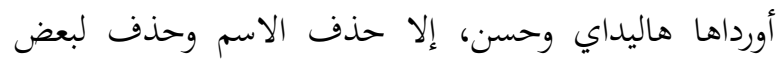
الضمائر، وحذف للجار والمجرور، وحذف لجملة واحدة.

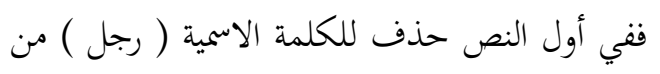

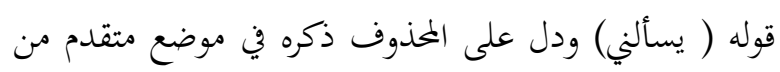

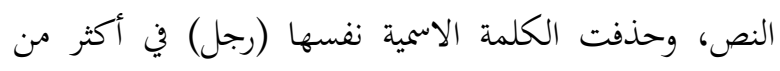
موضع وفي مجملها بعد لفظ القول وما اشتق منه، ( فقال التهال

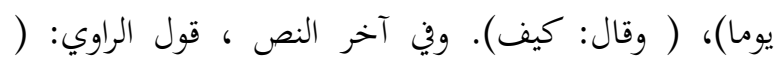
فسكت) أي: فسكت الرجل. ومن أكثر ما حذف من النص، المخل، المضمر فقد حذف النف

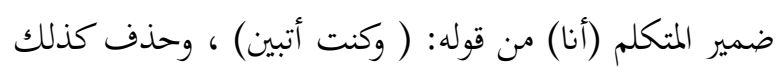

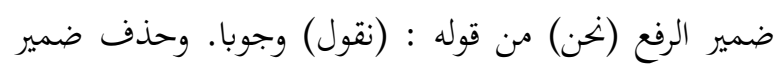
الرفع (أنت) من قوله: ( فتقول). أما حذف الجار والبمرور، فجاء في ثلاثة مواضع،

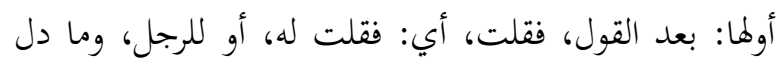

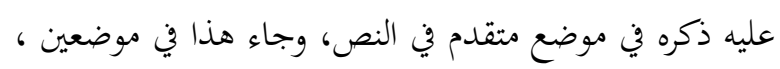

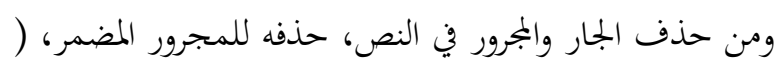
كم) من قوله:( تسوى)، أي: تسوى بكم. 
ويتم وظيفيّا لإنتاج فكرة النص أو إيصالها إلى المتلقي، فعماد

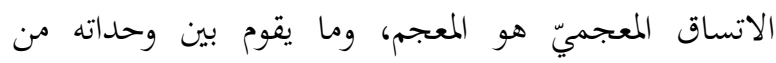

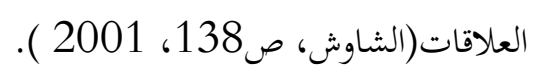

$$
\text { وينقسم الاتساق المعجمي إلى قسمين: }
$$

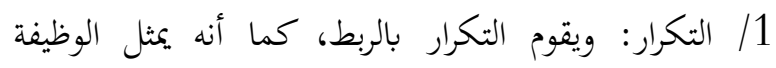

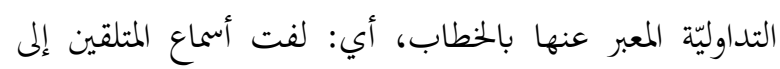

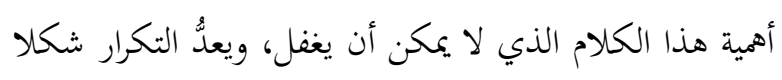

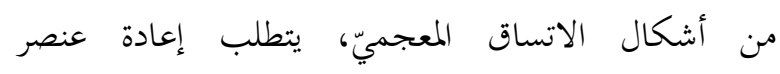

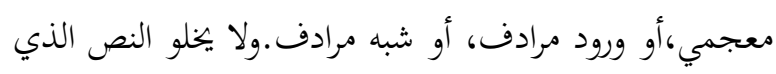
بين أيدينا منه . جاء التكرار في النص في تسعة مواضع، وأول هذه المواضع

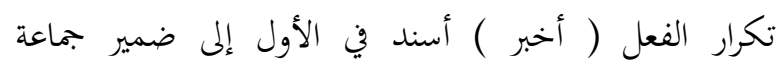

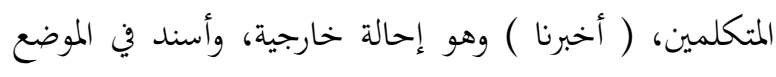
الثاني إلى ياء المتكلم ( أخبرني) وهذه إحالة إلى السائل، وهل إلها

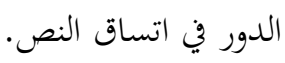
ومن التكرار الوارد في النص، تكرار لفظ القول، وما اشتق منه ( قال، نقول، فقلت، تقوله، فتقول، قوله) وفي

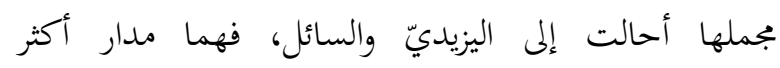

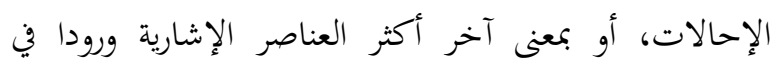
النص. ومن التكرار أيضا، قوله: " رجلا رجلا "، ومنه أيضا تكرار

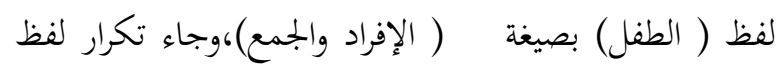

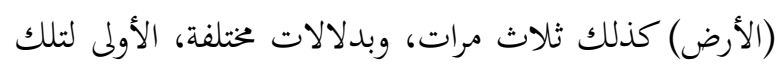
التي هم فيها الآن، والثانية والثالثة للأرض التي سيؤلون إليها.

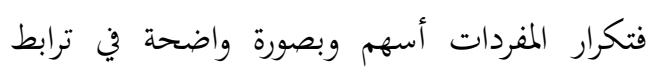
النص، وفي خلق نوع من الإحالة بين الكلمة والكلمة المكررة،

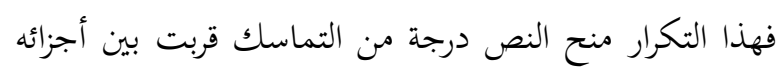
المتباعدة

2/ التضام: وهو توارد زوج من الكلمات بالفعل والقوة نظرا

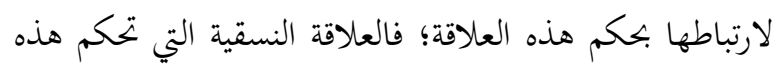

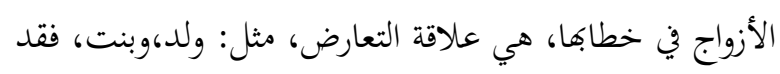

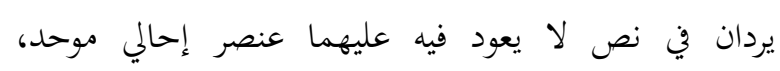

الذي يفيد ترتيبا باتصال، فقد تأخر المعطوف على المعطوف عليه متصلا، فالسؤال يأتي مباشرة بعد مجيئه. وعطف على هذين الفعلين أيضا، قوله : ( وكنت )

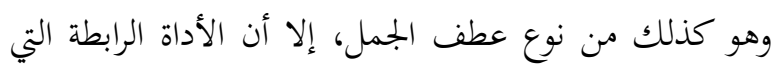

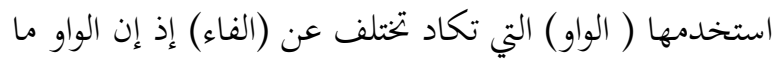
تفيد إلا إشراك الثاني فيما دخل فيه الأول، وليس فيها دليل

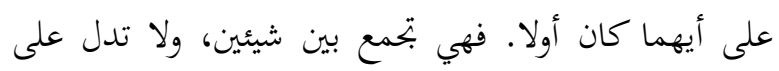
الترتيب فبمجيء الرجل يأتي السؤال، ومنه يتبين للمتلقي العنت فيما يطرحه من أسئلة. ومن عطف الجمل كذلك، قوله في النص: ( وكنت إذا أجبته أرى لونه يربد ويسود) فالرابط هنا جاء بالواو التي لوني

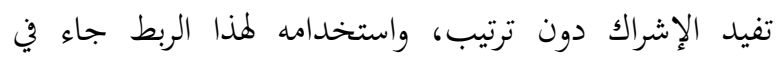
موضع آخر، وهو قوله : " والطفل مصدر يقع على الواحد والاثنين والجمع". موضع اخرك وهو وقد استخدم في النص رابطا غير هذين الرابطين،

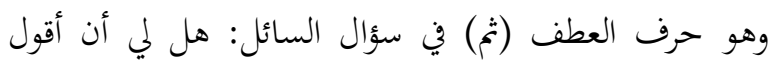

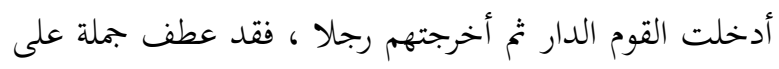
أخرى، إلا أن هذا الرابط يختلف عن الفاء في أفما يفيدان ترتيبا إلا أن الترتيب في (تم) يأتي بانفصال، أو تراخ.

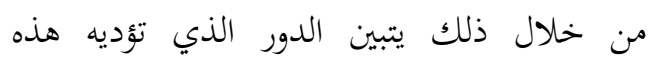
الأدوات في إحداث التماسك النصي، وما يتحقق هذا الاتساق إلا لسببين، أولمما: أن هذه الحروف تؤثر في تماسك التكات

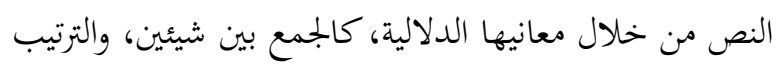

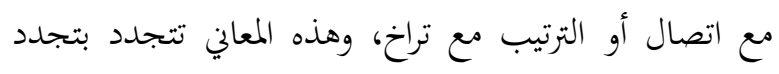

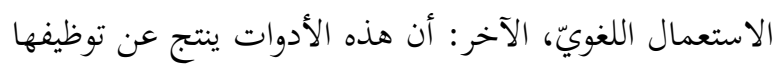

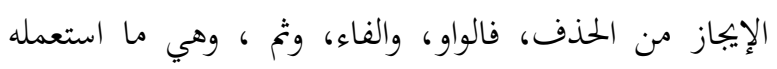

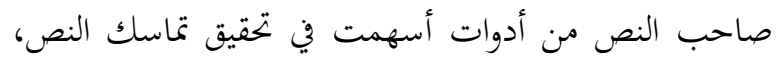
واتساقه بصورة بيّنة.

\section{رابعا: الاتساق المعجميّ:}

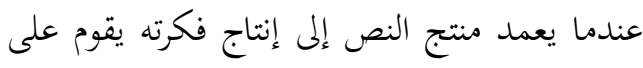

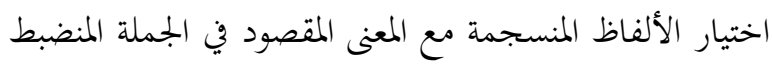

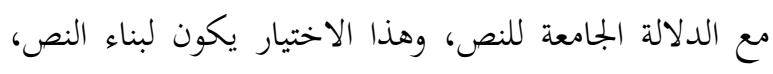


اللبس الدلاليّ في التركيب النحوي في الجملة. 4) أدوات

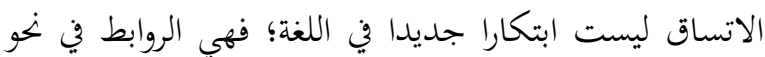
الجملة، ولكن التطور في الدرس اللغويّ أعطاها بعدا جديدا، وأصبح الباحثون ينظرون إلى مدى أثرها في تماسك النصوص؛

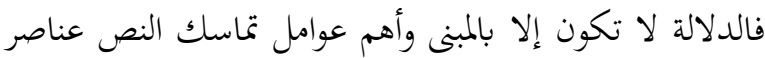

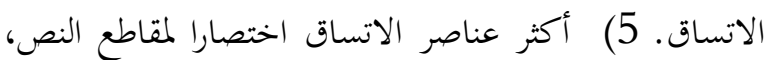

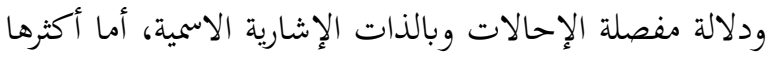
قدرة على إبراز العناصر الإشارية تخصيصا فهي الضمائر. 6)

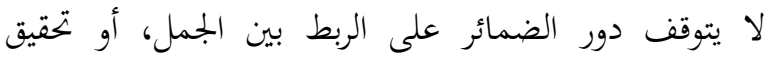
الترابط النصيّ على مستوى النص فحسب، بل لها كذلك دور

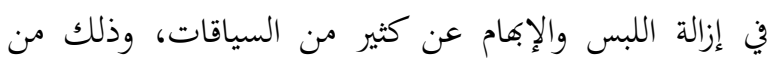

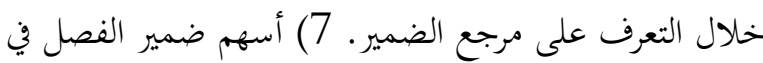

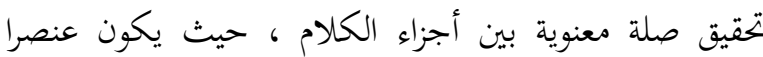
محيلا إلى سابق، فيكون بذلك عاملا قويا في التخصيص والتأكيد. 8) تقلص دور الحذف في النص بسبب الاستثمار الأمثل في الإحالات الضميرية التي أغنت عن تكرار الفاعل خاصة فاعل القول. 9) تؤثر حروف العطف في تماسك الإك العيك

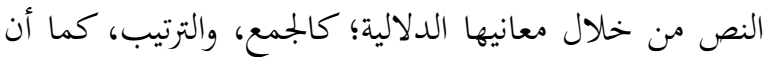

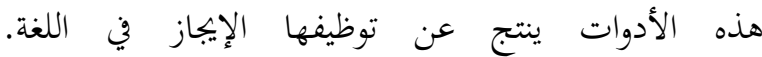

ولكنهما يسهمان في النصية. والتضاد والتنافر يؤديان إلى

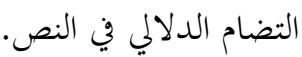

وما جاء التضام في النص إلا في موضع واحد فقط، وسبب ذلك صغر النص، وموضعه في النص، قوله: ( أدخلتُ)

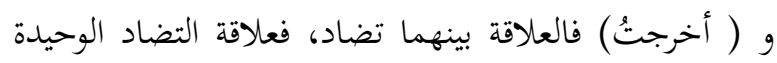
هذه أسهمت في اتساق النص وتماسكه.

الخاتمة

من خلال تحليل أثر عناصر الاتساق بأنواعها المختلفة في اتساق النص محل التحليل، توصلت الدراسة إلى النتائج

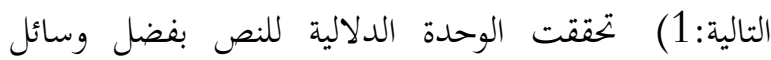
الاتساق المختلفة التي أشار إليها الباحث، وجمعت بين جمله

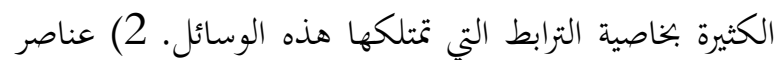
الاتساق في النص تكشف عن نصيته وخاصة العناصر الإحالية، وهذا ما تثبته الدراسة من خلال النص. 3) لعناصر

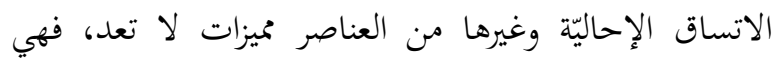
تعمل على اختصار الخبر النصيّ، كما تعمل على اختصار

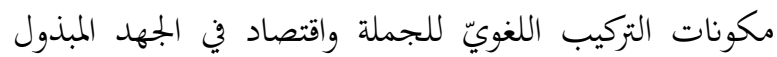

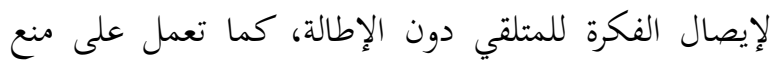

\section{REFERENCE}

al-Zujajii, Abi al-Qasim. (1980). Abi Al-Qasim Al-Zujaji. Baghdad. Dar al-Rashid lil Nash.

Amayirah, Khalil. (1989). Ad-Dlamir al-Aid. Muassasat al-Risalat lil Thibaah wa al-Nashr Dar-Furqan al-Shaawish, Muhammad. (2001). 'Uswal Tahlil al-Khitabi. Risalah Majistir. Tunis

Kharbusy, Miftah.(2008) al-Insijaam fi Diwan Ayat min Kitab al-Sahu. Risalat Majistir. Al-Jazair Universty

Na'us, Ibn Yahyaa Al-Taahir (1433) Balaghat al-Khithaab Diraasaat fi Taghayur al-Nusq al-Ma'rifii. Mutamar al-Lughat al-'Arabiah wa muwakabat al-'Asri. Islamic University of al-Madinah alMunawarah

Hasan, Tamam. (1993). al-Bayan fi Rawaai'i al-Quraan.'Alamu al-Kutub.

al-Harawi, Muhammad bin Ahmad al-Azhari. t: muhamad 'Awad mar'ab (2001). Tahdzib al-Lughah. Beirut. Dar Ihya Turots. 
'Arus, Miftah. (1997). Hawla al-Ittisaqi fi Nusus al-Marhalat al-Tsanawiah (Muqarabat Lisaniyah). Lecture and Language Arabic Journal.

al-Jurjani, ‘Abdul al-Qahir. t: Mahmud Syakir (1991). Dalail al-I'jaz. Maktabah al-Khaniji

Buhairi, Said. (1997). 'Ilmu Lughah al-Nash al-Mafahim wa al-ittijahat, al- Syarikah al-Misriyah al'Alamiyah. Longman, Maktabah Lubnan Nasyirun.

Barthes, Roland. t: Mundzir 'iyasyi. al-A'mal al-Kamila (1) ‘Imu Nash. Markaz al-Inma’ al-Hadlari.

al-Farahidi, Khalil bin Ahmad. t: Mahdi al-Mahzumi, Ibrahim al-Samiri. al-'Ain dar al-hilal.

al-Zamakhsari, Jar Allah. (1407) Al-Kassyaf 'an Haqaiq Ghawamidl al-Tanzil. Beirut. Dar al-Kutub al-Arabi

Ibn Ali, Muhammad bin mukram (ibnu mandzur al Anshari) (1414). Lisan al-Arab Beirut. Dar Shodir.

Khattabi, Muhammad. (1993) Lisaniyat al-Nash, Madkhal ila insijam al-khitab.Markaz tsaqafi alarabi.

Lyon,John. T: 'Abbas Shodiq al-wahhab. (1987) al-Lughah wa al-Ma'na wa al-Siyaq. Irak,dar al syuun al tsaqafiyah al 'Amah.

Afifi,Ahmad. (2001) Nahwa al-Nash Ittijah Jadid fi al-Dars al-Nahwi. Kairo, Maktabah Zahra' al Syarq.

al-Zinad, Al Azhar.(1993) Nasij al-Nash. Beirut, Markaz as Tsaqafi.

De Bujran,Robert. t: Tamam Hassan (1998) al-Nash wa al-Khithab wa al-Ijra'. 'Alam al-kitab 